\title{
Women Empowerment: Key to Socio-Economic Development Saima khan
}

Institute of Life Sciences, Chongqing Medical University, China

Corresponding author email ID: saima@aeirc-edu.com

\begin{abstract}
Background: Empowering a women is the key issue in developing nations. Despite of the fact that women are an integral part of any society, yet their involvement in decision making via their active contribution in economic activities is very low. Women empowerment and economic development are interlinked, where on one hand, development alone can play a major role in driving down inequality between women and men while on the other hand, empowering women can benefit development.

Methodology: A short communication of 5 years i.e. 2014-2018. Databases used were Google Scholar, PubMed, Research gate, Scopus and web of science.

Results: Providing consideration of working at individual consciousness level in order to develop women's sense of their own potentials and critical recognitions of the obstacles within social dimensions, so that women identifies their potentials and put efforts together with other women like a distinctive power to confront inequalities and injustice, will turn out to be 'power for' positive societal modifications. Also setting resources in hands of underprivileged women while discouraging gender inequality not only at home but also in society results in enormous development settlements. Those Expanding opportunities for women's in communal works, investment, agricultural and further areas hasten economic progression, helping to lessen the effects of current and future financial crises.

Conclusion: For improving quality of life there is high necessity of fundamental alterations. Policies should be created to improve the women status as useful society members. There is a high necessity of women's active participation not only in decision making processes but also in planning and implementation of development programs.
\end{abstract}

Women Empowerment, Karo-Kari, Watta-Satta, Gender Based Violence

\section{Introduction}

The accurate meaning of word empowerment is to give or permit power. In this context we can say, creating resources and offers networks through which women shares equal human rights as men is identified as women empowerment. Since eras women rights have been desecrated (Cole, 2017). Globally, this violation is not limited to some parts, in fact almost in all states women's rights have been violated in one way or any other way. Women deserves an equal say in everything from their right of full access to education to right for voting (Cole, 2017).

It can be defined as a route leading towards improving women's ability to control financial, social and intellectual resources of the nations, measured by women's level of involvement in economic, social and political grounds (Rehman et al., 2015). Women can only be truly empowered when all the aspects for instance women's selfesteem, controlling their lives by their own, their capability to bring out social changes, are addressed all together (Cornwall, 2016). Although half of total proportions of world's populace are women, still their basic rights are deprived in most developing countries all over the world. Due to pervasiveness gender discrimination, women lives are under destitution, most specifically in the southern and eastern Asian countries (D. Chant \& McIlwaine, 2015).
According to united nations research survey of Pakistan, 50\% women are physically battered in addition to this $90 \%$ of women population are verbally and mentally abused by their men relatives (Jacobson, 2018), whereas an additional study conducted by women divisions on "Battered housewives in Pakistan" shows $80 \%$ of women facing domestic violence (Bhattacharya, 2014). Another recent report by human rights commission states 400 cases of domestic violence annually, in which half of victim dies (Gill et al., 2017).

The situation is more verse in Sindh and Baluchistan provinces where Karokari and Watta Satta are openly practiced (Shoro, 2017). A woman is expected to uphold her family honor at every cost and if she did something that is assumed to effect family honor then she is anticipated to be immoral and is declared as Kari while Karo is a man assumed to be her lover. Her husband or in laws give her death as a penalty of suspected infidelity while the assassin goes unpunished as he is regarded as person who retrieves the lost family honor (Jamali \& Shah, 2015).

Another worse tradition practiced in different regions of Pakistan is Watta Satta. In this girl has to marry brother of her sister in law. This tradition often leads to very complicated situation in which woman has to payback for her brother mistakes of mistreating and abusing his wife. As a result that woman turns into a mere object of revenge (Bhutta et al., 2015) 
Man satisfies their aggressive desires by humiliating his wife. Annually, thousands of women dies or mutilated by stove-burns. The purpose behind this mistreating is to get rid of that women so husband will remarry to get more dowries (Anitha et al., 2018).

\section{Methodology}

A short communication of 5 years i.e. 2014-2018. Databases that were used included Google Scholar, PubMed, Research gate, Scopus and web of science. While media channels and news reports were also included.

\section{Results}

In modern era social media is significantly progressing and plays a major role not only in highlighting and fighting against women in Pakistan but also a great way of providing awareness to women about their rights and potentials. Recently social media in Pakistan are the main reason behind various highlighted cases, in which social media helped in attaining justice for some of the victims. The significant highlights include:

$>$ Suman Ali acid attack case.

$>$ Zainab murder case.

$>$ Khadija Siddiqui was attacked by her class fellow Shah Hussain, who stabbed her 23 times and injured her younger sister as well.

$>$ Dunga Gali murder case.

Though, it is also a tragedy that women in Pakistan have also victimized for the reason of the content been uploaded on social media, in the name of 'honor'. Their social media posts have resulted in honor killings by relatives or close family members, which includes:

$>$ The Kohistan case resulted in terrible murders of 2 boys and 5 girls due to a video on social media.

$>$ Qandeel Baloch murder case.

\section{Discussion}

Different patterns of abusive actions and control generally involves domestic violence, beating and intimate partner exploitation. Mental torture, constantly underestimating, bullying, dishonoring, forced sex and assaults like kicking, slapping, hitting are counted as partner's abusive behaviors (Velonis, 2016). Frequently it may include behaviors for instance keep women isolated from her friends and family, restriction in getting access to different resources and checking her every moment. Physical violence in these type of relations is done mostly along with psychological abuse and in some case with sexual abuse as well (Walker, 2016).

The psychological effects as consequence of abuse are much more severe than its physical effects. This experience of women on being abused eats away her self-esteem and increases her risk for other mental illnesses like post-traumatic stress disorder, suicidal thoughts even attempts to suicide, depression, intake of high quantity of drugs and alcohols (Heise, 2018 \& Khan et al., 2015).

A woman's responses is frequently restricted by herself via the preferences available to her. Fear of reprisal, lack of economic support, worries for her children, emotional necessities, not supported by family and friends, and unshakeable false hope that her husband may change are mostly the reasons that women repetitively gives to stay in relationship. In Pakistan divorce continues to be something that is prohibited by society for any woman (Ali, 2018). As a result this fear of social stigma stops women from getting any support. Studies shows approximately $70 \%$ of abused women never shares their experiences with anyone (Reeves \& Humphreys 2018).

Different norms and believes are responsible for violence against women. Some of these includes the concepts that men are superior to women inherently, it is men's duty and right to discipline women, and women's sexual activities is connected to male or her family honor and no one can interfere on victim's behalf as it is considered as private issues that can only be handle by the intimate partners by their own (Veen et al., 2018). Women's must unite effectively and any effort even a smallest one in this path should be considered concerning the objective of bringing out any social transformation leading towards sign of stability among masculine and feminine powers of the societies (Veen et al., 2018).

Modern-day societies throughout the world have been exposed to the major routes of alteration on economic and social front. Still, the practices have not been applied in balanced way and have increased gender inequities all over the world in which women continued to be the serious victim (Basu, 2018). Therefore, for achieving the goal of women empowerment entirely and perfectly, women must turn out to be energetic and dynamic partners with males. Also to make the efforts leading to successful transformation of society, it is crucial to take along women in the mainstream of advancements. We need to strike a perfect equilibrium concerning male and female contributors in rural civilizations by providing equivalent chances to women deprived of being biased concerning men.

\section{Conclusion}

There must be programs aimed to change those dogmas and must encourages women and other people to discuss this violence rather than antagonizing or alienating them by giving the impression of 'demonize' men. TV and theater plays are very good techniques now-a-days in encouraging people to develop new norms.

Health care providers can play a significant role. Victims must be recognized and helped by health 
care providers by illuminating legal support, guidance counselor and non-governmental organizations. They can play significant role in preventing serious conditions and serious effects. But sadly many doctors and nurses don't take interest in asking women about their experiences with violence and if any one ask for help even then they are not ready to positively respond to the victim's requests.

\section{Conflicts of interest}

None.

Acknowledgement

I would like to thank all previous researchers who worked in this domain.

\section{Funding}

None.

\section{References}

- Ali, P. A., O’Cathain, A., \& Croot, E. (2018). Influences of extended family on intimate partner violence: perceptions of Pakistanis in Pakistan and the United Kingdom. Journal of interpersonal violence, 0886260518785378.

- Anitha, S., Yalamarty, H., \& Roy, A. (2018, August). Changing nature and emerging patterns of domestic violence in global contexts: Dowry abuse and the transnational abandonment of wives in India. In Women's Studies International Forum (Vol. 69, pp. 67-75). Pergamon.

- B. Cole, M. (2017). Education, equality and human rights: issues of gender,'race', sexuality, disability and social class. Routledge.

- Basu, A. (2018). The challenge of local feminisms: Women's movements in global perspective. Routledge.

- Bhattacharya, S. (2014). Status of women in Pakistan. Journal of the Research Society of Pakistan, 51(1).

- Bhutta, R. N., Warich, I. A., Bhutta, A., Bhutta, N. I., \& Ali, M. (2015). Dynamics of Watta Satta Marriages in Rural Areas of Southern Punjab Pakistan. Open Journal of Social Sciences, 3(12), 166.

- Cornwall, A. (2016). Women's empowerment: What works? Journal of International Development, 28(3), 342359.

- D. Chant, S., \& McIlwaine, C. (2015). Cities, slums and gender in the global south: Towards a feminised urban future. Routledge.

- Gill, F., Phull, G. M., \& Chachar, A. A. (2017). Human Rights Violations of Labour and Women In Pakistan. Grassroots, 51(1).

- Heise, L. (2018). Violence against women: the missing agenda. In The health of women (pp. 171-196). Routledge.

- Jacobson, J. L. (2018). Women's health: The price of poverty. In The Health of Women (pp. 3-32). Routledge.

- Jamali, H., \& Shah, N. A. (2015). The origin of honour killing (karo-kari) in Sindh Pakistan: a discussion on Islamic context. The Women-Annual Research Journal of Gender Studies, 7.

- Khan, K. S., Rafique, G., Bawani, S. A. A., Hasan, F., \& Haroon, A. (2015). Social and societal context of women's mental health, what women want, what they get: gap analysis in Pakistan of mental health services, polices and research. In Women's Mental Health (pp. 33-50). Springer, Cham.

- $\quad$ Reeves, E. A., \& Humphreys, J. C. (2018). Describing the healthcare experiences and strategies of women survivors of violence. Journal of clinical nursing, 27(56), 1170-1182.

- Rehman, H., Moazzam, A., \& Ansari, N. (2015). Role of microfinance institutions in women empowerment: A case study of Akhuwat, Pakistan. South Asian Studies, 30(1), 107.

- Shoro, S. (2017). Honour Killing in the Second Decade of the 21st Century. Cambridge Scholars Publishing.

- Veen, S., Moorten, R., \& Durani, W. (2018). Marriage Decision-Making: A family affair-Insight into marriage decision-making processes and social norms around child marriage in Larkana and Shikarpur in Sindh and Lodhran and Muzaffargarh in Punjab, Pakistan.

- Velonis, A. J. (2016). "He Never Did Anything You Typically Think of as Abuse" Experiences With Violence in Controlling and Non-Controlling Relationships in a Non-Agency Sample of Women. Violence against women, 22(9), 1031-1054.

- Walker, L. E. (2016). The battered woman syndrome. Springer publishing company. 